\title{
Investigation of the Polymorphism of Osmium Tetrachloride ${ }^{1}$
}

\author{
Paul Machmer* \\ Institute of Inorganic Chemistry, University of Cologne, Germany
}

(Z. Naturforschg. 24 b, 200-205 [1969] ; eingegangen am 7. August 1968)

\begin{abstract}
Depending on the method of preparation, osmium tetrachloride may be obtained in two different crystalline modifications, namely the high-temperature and the low-temperature forms. Both these species have been identified by elemental analysis and characterised by their respective $\mathrm{x}$-ray powder photographs and magnetic susceptibilities. The x-ray powder data of the high-temperature form are tentatively rationalized in terms of an orthorhombic unit cell with the following dimensions: $a=12.08 \AA, b=11.96 \AA$ and $c=11.68 \AA$. From the $\mathrm{x}$-ray powder digram of the lowtemperature form the cubic lattice constant $a=9.95 \AA$ is deduced. Reflection conditions for hkl and h00 are indicative of the space groups $0^{6}\left(\mathrm{P}_{3} 32\right)$ and $0^{7}\left(\mathrm{P}_{1} 32\right)$. Both compounds are paramagnetic and display low magnetic susceptibilities as a consequence of strong spin-orbit coupling. The high-temperature form exhibits the temperature-independent magnetic susceptibility $\chi_{\mathrm{mole}}=$ $+1080 \times 10^{-6}$ c.g.s. units, whereas for the low-temperature form the value is $\chi_{\text {mole }}=+880 \times 10^{-6}$ c.g.s. units (at $300^{\circ} \mathrm{K}$ ). The latter susceptibility is temperature dependent. Some regularities between the uptake of chlorine by second- and third-row transition metals and the first ionization potential of the metals involved are discussed.
\end{abstract}

Octahedrally co-ordinated osmium(IV) complexes with chlorine atoms as ligands are of theoretical interest, largely as a result of their magnetic behaviour. Hence numerous studies on this class of substances have been reported in the last few years, dealing not only with bulk magnetic susceptibilities ${ }^{2 a-d}$ but covering the main features of the respective electronic ${ }^{3 a-b}$, vibrational ${ }^{4}$ and nuclear quadrupole resonance spectra ${ }^{5}$. Since no such data have yet become available for osmium tetrachloride itself, some results relevant to this chloride will be presented in this paper, thus supplementing earlier investigations ${ }^{6 a-e}$ of noble metal halides.

$\mathrm{Up}$ to the present time, $\mathrm{OsCl}_{4}$ has been synthesized from its elements ${ }^{7-9}$, this product being the hightemperature form. The reaction is carried out either in an open reaction vessel ${ }^{7,8}$ or, as recently sug-

* Present address : Department of Chemistry, The University, Leicester, England.

1 Part of this work has appeared previously in communication form; see P. Machmer, Chem. Commun. [London] 1967, 610 .

2 a) R. B. Johannesen and A. R. Lindberg, J. Amer. chem. Soc. 76, 5349 [1954]; b) V. I. Belova, Zhur. Neorg. Khim. 3, 2016 [1958]; c) A. Earnshaw, B. N. Figgis, J. Lewis, and R. D. Peacock, J. chem. Soc. [London] 1961, 3132; d) R. B. Johannesen and G. A. Candela, Inorg. Chem. 2, 67 [1963].

3 a) C. K. Joergensen, Acta chem. scand. 16, 793 [1962] ; b) C. K. Joergensen, Acta chem. scand. 17, 1034, 1043 [1963].

4 P. J. Hendra and P. J. D. Park, Spectrochim. Acta [London] 23 A, 1635 [1967].

5 K. Ito, D. Nakamura, K. Ito, and M. Kubo, Inorg. Chem. 2, 690 [1963]. gested ${ }^{9}$, in a sealed tube. Only recently it was found ${ }^{10}$ that osmium metal and $\mathrm{SO}_{2} \mathrm{Cl}_{2}$ yielded the high-temperature form of $\mathrm{OsCl}_{4}$ at $733{ }^{\circ} \mathrm{K}$. This latter procedure is the only modification of the original approach $^{7}$ since 1910. Therefore other methods of synthesis were investigated; in particular, the reaction of $\mathrm{OsO}_{4}$ with $\mathrm{CCl}_{4}$ yielded the high-temperature form of $\mathrm{OsCl}_{4}$. Further, a new crystalline modification ${ }^{1}$ (low-temperature form) of $\mathrm{OsCl}_{4}$ was obtained from the reaction of $\mathrm{OsO}_{4}$ and $\mathrm{SOCl}_{2}$, thus extending the number of elements in the third transition metal group which are known to form polymorphous ${ }^{11 a-c}$ chlorides.

The two crystalline modifications of $\mathrm{OsCl}_{4}$ were characterised by x-ray diffractometry and magnetic measurements, the following results being obtained:

${ }^{6}$ a) K. Brodersen and P. Machmer, Z. Naturforschg. 17 b, 127 [1962]; b) P. Machmer, M. ReAd and P. Cornil, C.R. hebd. Séances Acad. Sci. 262, 650 [1966] ; c) P. Machmer, Inorg. nuclear Chem. Letters 4, 91 [1968]; d) P. MACHMER, Z. Naturforschg. 23 b, 295 [1968]; e) P. Machmer, J. inorg. nuclear Chem. 30, 2627 [1968].

7 O. Ruff and F. Bornemann, Z. anorg. allg. Chem. 65, 446 [1910].

8 R. L. SchaAf, J. inorg. nuclear Chem. 25, 903 [1963].

9 N. I. Kolbin, I. N. Semenov, and Yu. M. Shutov, Russ. J. inorg. Chem. 8, 1270 [1963].

10 D. A. EDWARD and A. A. WOOLF, J. chem. Soc. [London] 1966, 92.

11 a) K. Brodersen, Angew. Chem. 73, 437, 761 [1961]; b) K. Brodersen, F. Moers, and H. G. Schnering, Naturwissenschaften 52, $205[1965]$; c) D. BABEL and P. Deigner, Z. anorg. allg. Chem. 339, 57 [1965]. 
Results of $x$-ray powder diffractometry

The two modifications of $\mathrm{OsCl}_{4}$ differ in their x-ray powder patterns. The $\mathrm{Br}$ ag g angles $\vartheta$ of the high-temperature form as prepared from $\mathrm{OsO}_{4}$ and $\mathrm{CCl}_{4}$ are shown in table 1 .

\begin{tabular}{rrrrr}
\hline No. & $\begin{array}{c}\text { Inten- } \\
\text { sity }\end{array}$ & $\begin{array}{c}\vartheta \text { ob- } \\
\text { served }\end{array}$ & d-spacing & $\begin{array}{c}\text { d-spacing } \\
\text { (see loc. } \\
\text { cit. } 9 \text { ) }\end{array}$ \\
\hline 1 & 10 & 7.7 & 5.7487 & \\
2 & 5 & 10.6 & 4.1872 & \\
3 & 5 & 11.2 & 3.9656 & \\
4 & 4 & 12.5 & 3.5587 & \\
5 & 6 & 14.7 & 3.0354 & 3.02 \\
6 & 8 & 16.5 & 2.7120 & 2.70 \\
7 & 4 & 17.7 & 2.5334 & 2.51 \\
8 & 9 & 18.2 & 2.4661 & 2.46 \\
9 & 3 & 20.1 & 2.2413 & 2.23 \\
10 & 4 & 21.4 & 2.1110 & 2.10 \\
11 & 3 & 21.9 & 2.0651 & 2.05 \\
12 & 3 & 22.8 & 1.9877 & 1.98 \\
13 & 2 & 23.7 & 1.9163 & 1.905 \\
14 & 2 & 25.4 & 1.7957 & 1.792 \\
15 & 9 & 26.1 & 1.7508 & 1.738 \\
16 & 4 & 27 & 1.6966 & 1.685 \\
17 & 3 & 28 & 1.6407 & 1.627 \\
18 & 3 & 28.8 & 1.5988 & 1.591 \\
19 & 2 & 32 & 1.4535 & 1.445 \\
20 & 6 & 32.6 & 1.4296 & 1.419 \\
\hline
\end{tabular}

Table 1. B r a g g angles $\vartheta$ of the low-temperature form of $\mathrm{OsCl}_{4}$.

In contrast, the $\mathrm{x}$-ray powder photograph of $\mathrm{OsCl}_{4}$ as synthesized from the basic materials $\mathrm{OsO}_{4}$ and $\mathrm{SOCl}_{2}$ is simple and consists only of 11 lines.

\begin{tabular}{rrrrc}
\hline No. & $\begin{array}{c}\text { Inten- } \\
\text { sity }\end{array}$ & $\begin{array}{c}\vartheta \text { ob- } \\
\text { served }\end{array}$ & hkl & $\begin{array}{c}\vartheta \text { cal- } \\
\text { culated }\end{array}$ \\
\hline 1 & 10 & 7.7 & 111 & 7.7 \\
2 & 4 & 14.9 & 311 & 14.9 \\
3 & 10 & 18.1 & 400 & 18.0 \\
4 & 3 & 19.8 & 331 & 19.7 \\
5 & 4 & 23.8 & 333 & 23.7 \\
6 & 10 & 26 & 440 & 26 \\
7 & 3 & 27.3 & 531 & 27.3 \\
8 & 3 & 31 & 622 & 30.9 \\
9 & 7 & 32.5 & 444 & 32.4 \\
10 & 2 & 33.6 & 551 & 33.6 \\
11 & 3 & 38.5 & 800 & 38.3 \\
\hline
\end{tabular}

Table II. B r a g g angles $\vartheta$ of the low-temperature form of $\mathrm{OsCl}_{4}$.

The x-ray powder photographs of both $\mathrm{OsCl}_{4}$ modifications display no lines originating from osmium metal.

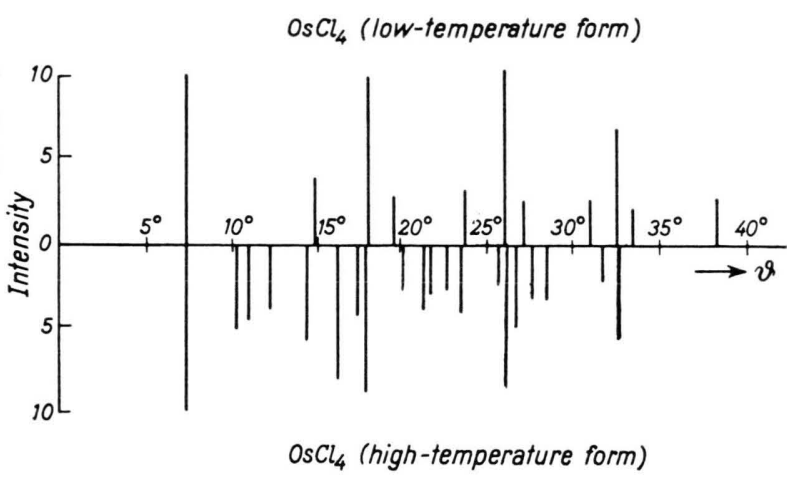

Fig. 1. Schematic diagram of the x-ray patterns of the highand the low-temperature forms of $\mathrm{OsCl}_{4}$.

\section{Discussion of the $x$-ray data}

An important feature of the x-ray powder photographs of the high-temperature form presented in this work are 4 lines in the low-angle region, which were not observed by KolBIN ${ }^{9}$ and his coworkers. It is to be stressed that in the present investigation these 4 lines (those labelled with the numbers $1-4$ in table I) were recorded in every high-temperature specimen of $\mathrm{OsCl}_{4}$ irrespective of the preparation procedure involved i. e. from the elements or from $\mathrm{OsO}_{4}$ and $\mathrm{CCl}_{4}$. These results undoubtedly confirm that these 4 lines are real. Moreover, they do not originate from osmium metal or osmium trichloride. Therefore they must be taken into account when the unit cell dimensions of $\mathrm{OsCl}_{4}$ are evaluated. In particular, the x-ray data in table I can be tentatively rationalized in terms of an orthorhombic unit cell with the following dimensions: $a=12.08 \AA, b=$ $11.96 \AA$ and $c=11.68 \AA$. However, this preliminary conclusion must await final verification by investigation of single crystals which have not yet become available.

More structural information is available on the low-temperature form. Specifically, the x-ray data given in table II yielded the cubic lattice constant $a=9.95 \AA$. On the basis of the recorded x-ray powder pattern the conditions for reflection were observed to be:

hk1: no conditions

h00: $h=4 n$.

These reflection conditions ${ }^{12}$ are indicative of the space groups $\mathrm{O}^{6}\left(\mathrm{P}_{3} 32\right)$ and $\mathrm{O}^{7}\left(\mathrm{P}_{1} 32\right)$. 


\section{Results of the magnetic measurements}

Both forms of $\mathrm{OsCl}_{4}$ are paramagnetic. Their molar susceptibilities at $300{ }^{\circ} \mathrm{K}$, corrected for the diamagnetism of the ligands ${ }^{13}$, are $+1080 \times 10^{-6}$ c.g.s. units for the high-temperature form and $+880 \times 10^{-6} \mathrm{c.g}$. s. units for the low-temperature form. These values correspond to effective magnetic moments of 1.6 and 1.4 B.M. respectively. According to the data in table III, the paramagnetic susceptibility of the high-temperature form is temperatureindependent, whereas the susceptibility of the lowtemperature form varies with temperature:

\begin{tabular}{cc}
\hline & $\begin{array}{c}\text { molar susceptibilities } \\
(\text { corrected }) \\
{\left[\times 10^{-6}\right]}\end{array}$ \\
\hline & \\
\hline a) $\mathrm{OsCl}_{4}$ (high-temperature form) \\
373 & +1092.4 \\
300 & +1080 \\
195 & +1099 \\
77 & +1083 \\
& \\
b) $\mathrm{OsCl}_{4}$ (low-temperature form) \\
373 & +828.4 \\
300 & +880 \\
195 & +976 \\
77 & +1129.3
\end{tabular}

Table III. Temperature dependence of the molar susceptibilities of the two modifications of $\mathrm{OsCl}_{4}$.

In this contect it should be mentioned that after the communication of our data in $1967^{1}$, Colton and FARTHING ${ }^{14}$ published in 1968 magnetic data of the low-temperature form which differ from the values presented in table III.

In order to supplement the results of the bulk susceptibility measurements, EPR-spectroscopy was used in an attempt to investigate the high-temperature form in the solid state. However, no EPR-signal could be observed in the $\mathrm{x}$-band region, either at $300{ }^{\circ} \mathrm{K}$ or at $83{ }^{\circ} \mathrm{K}$.

\section{Discussion of the magnetic results}

$\mathrm{Os}^{4 \oplus}$ is characterised by the electron configuration $5 \mathrm{~d}^{4}$, the $5 \mathrm{~d}$-orbitals being five fold degenerate in the free metal ion. However, in the solid state, the $\mathrm{Os}^{4}{ }^{\odot}$ ions of the crystalline compounds $\mathrm{OsCl}_{4}$ are subjected to the inflence of an electrostatic field ori-

12 International Tables for x-ray Crystallography 1, 321 [1965], The Kynoch Press, Birmingham.

13 P. SELWOOD, Magnetochemistry, Second Edition, page 78, Interscience Publishers, London 1956. ginating from the chloride anions. As a consequence of this perturbation and of the spin-orbit coupling, the degeneracy of the $5 \mathrm{~d}$-orbitals is lifted. On the basis of the space groups $\mathrm{O}^{6}$ and $\mathrm{O}^{7}$ it is concluded that in the low-temperature form the $\mathrm{Os}^{4 \oplus}$ ions are basically octahedrally co-ordinated by the chloride anions which are in turn the source of an electrostatic field of near cubic symmetry. As for the hightemperature form, a similar co-ordination of $\mathrm{Os}^{4 \oplus}$ by chloride anions is assumed. From grouptheoretical calculations ${ }^{15}$ it is known that unter these conditions the fivefold degenerate 5 d-orbitals are split into two, energetically different sets of orbitals, assigned as $\mathrm{T}_{2 \mathrm{~g}}$ and $\mathrm{E}_{\mathrm{g}}$ respectively. In accommodating the four electrons of $\mathrm{Os}^{4}{ }^{\oplus}$, the energetically favoured $T_{2 g}$ orbitals will be occupied preferentially by them, thus giving rise to a low-spin state with two unpaired electron spins. Consequently a spinonly magnetic moment of $2.83 \mathrm{~B} . \mathrm{M}$. is to be expected for osmium(IV) compounds. However, it must be pointed out that a magnetic moment of 2.83 B.M. has never yet been observed in osmium (IV) compounds. Therefore the following questions are to be raised and dealt with:

I) Why are the experimental values of the magnetic moments of the osmium tetrachlorides considerably lower than the spin-only value of 2.83 B.M.?

II) Why is the molar susceptibility of the hightemperature form greater than the molar susceptibility of the low-temperature form?

In reply the question I, the deviation from 2.83 B.M. may be attributed to at least two factors:

a) The action of strong spin-orbit coupling,

b) Magnetic exchange interactions between the magnetic moments of $\mathrm{Os}^{4 \oplus}$ ions.

In particular, the dependence of the magnetic susceptibility upon the spin-orbit coupling constant is described approximately ${ }^{16}$ by the following equation (1)

$$
\chi=\frac{24 \times N \times \beta^{2}}{\zeta}
$$

provided that $\zeta \gg k T$. The latter condition also accounts for the temperature independence of the

14 R. Colton and R. H. Farthing, Australian J. Chem. 21, 591 [1968].

15 H. A. Bethe, Ann. Physik. 3, 133 [1929]. 
magnetic susceptibility if $N=$ Avogadro's number. $\beta=\mathrm{B}$ o h r's Magneton $\left(0.92732 \times 10^{-20} \mathrm{erg} /\right.$ Gauss $)$. $\zeta=$ single-electron spin-orbit coupling parameter. From spectroscopic investigations a value of $\zeta=$ $4500 \mathrm{~cm}^{-1}$ was obtained ${ }^{17 \mathrm{a}-\mathrm{b}}$ which explains on the basis of equation (1) why the magnetic moments of the $\mathrm{OsCl}_{4}$-modifications are considerably smaller than 2.83 B.M.

Not only spin-orbit coupling but also strong magnetic interactions between adjacent $\mathrm{Os}^{4}{ }^{\oplus}$ ions account for the reduced magnetic moment of 1.4 B.M. The latter effect has already been demonstrated ${ }^{18}$ in salts containing the anion $\mathrm{OsCl}_{6}{ }^{2}{ }^{\ominus}$ as a dope in a suitable diamagnetic host lattice. As a result of this dispersion in a diamagnetic matrix, the distances between neighbouring $\mathrm{Os}^{4 \oplus}$ ions become greater than in the undiluted osmium(IV) complex. Consequently, magnetic exchange interactions become less important and because of this, the magnetic moment of $\mathrm{Os}^{4 \oplus}$ is greater than in the pure material. A similar phenomenon can be observed in the case of the $\mathrm{OsCl}_{4}$-modifications.

As for question II, the dependence of the molar susceptibility of the low-temperature form upon temperature is taken as evidence of strong intermediate magnetic coupling effects which account for the lower susceptibility of this modification. Conversely, the enlarged lattice dimensions of the high-temperature form are paralleled by an increased magnetic moment and by analogy with the doping experiment ${ }^{18}$, this behaviour is interpreted in terms of reduced magnetic interactions between $\mathrm{Os}^{4}{ }^{\oplus}$ ions which are now separated from each other by greater interatomic distances.

As has been noted previously ${ }^{19}$ for osmium(IV) complexes, the negative results of the EPR-measurements on $\mathrm{OsCl}_{4}$ may be due to magnetic interactions causing lines which are too broad to be detected (spin-spin broadening).

16 M. Kotani, J. physic. Soc. Japan 4, 293 [1949].

17 a) J. S. Griffith, The Theory of Transition Metal Ions, page 284, University Press, Cambridge 1961 ; b) B. N. Figgis and J. LEwIS, Progr. inorg. Chemistry 6, 165 [1964].

18 A. D. Westland and N. C. Bhiwandker, Canad. J. Chem. 39, 1284 [1961].

19 W. Low, Paramagnetic Resonance in Solids, page 112, Academic Press, London-New York 1960.

20 K. Knox, S. Y. Tyree, R. D. Srivastaya, V. Norman, J. Y. Bassett, and J. H. Holloway, J. Amer. chem. Soc. 79, 3358 [1957].

21 R. Colton, Nature [London] 194, 374 [1962].
Some remarks on a correlation between the different uptake of chlorine by transition metals and the first ionization potential of the metals involved

Until now no higher osmium chloride than $\mathrm{OsCl}_{4}$ has been found to exist at $300{ }^{\circ} \mathrm{K}$. Even the reaction of $\mathrm{OsO}_{4}$ with $\mathrm{CCl}_{4}$ yielded only $\mathrm{OsCl}_{4}$, although this type of reaction is known to produce metal chlorides with the metal in its highest valence state ${ }^{20}$. In this respect osmium differs sharply from rhenium which exists at $300{ }^{\circ} \mathrm{K}$ as pentachloride and even as hexachloride ${ }^{21}$.

It is the aim of this concluding paragraph to point out that the different uptake of chlorine by these two metals can be rationalized by consideration of their first ionization potentials. Indeed, it is gratifying to see that the ability of rhenium to exist at $300{ }^{\circ} \mathrm{K}$ as a hexachloride ${ }^{21}$ is paralleled by a lower first ionization potential $(7.87 \mathrm{ev})^{22}$ than that of osmium, whose first ionization potential ${ }^{23}$ is $8.7 \mathrm{ev}$. This higher value is presumably the limiting factor which prevents the existence of osmium chlorides higher than $\mathrm{OsCl}_{4}$ (at $300{ }^{\circ} \mathrm{K}$ ). This correlation between the first ionization potential of the metal and the highest valence-state chloride at $300^{\circ} \mathrm{K}$, as established in this particular case, is of general validity as is demonstrated by inspection of figs. 2 and 3 which represent the first ionization potentials of tungsten ${ }^{22}$, rhenium ${ }^{22}$. iridium ${ }^{24}$, platinum ${ }^{25}$ and gold ${ }^{26}$ (and of molybdenum ${ }^{22}$, technetium ${ }^{22}$, ruthenium ${ }^{22}$, rhodium ${ }^{27}$ and palladium ${ }^{22}$ respectively) as function of their highest valence-state chlorides at $300{ }^{\circ} \mathrm{K}$ :

It can be seen on fig. 2 and fig. 3 that the metals existing at $300{ }^{\circ} \mathrm{K}$ as high valence-state chlorides are characterised without exception by lowest ionization potentials and vice versa. This simple rule accounts also for the ability of platinum to exist as tetrachloride at $300{ }^{\circ} \mathrm{K}$.

Although there is no theoretical basis for correlating the abilities of these transition metals to

22 V. I. Vedeneyev, L. V. Gurvich, V. N. Kondrat'yev, V. A. Medvedev, and Ye. L. Frankevich, Bond EnergiesIonization Potentials and Electron Affinities, page 152, Translated from the Russian, Arnold Publishers, London 1966.

23 W. Albertson, Physic. Rev. (2) 45, 307 [1934].

24 W. Albertson, Physic. Rev. (2) 54, 184 [1938].

25 J. J. Livingood, Physic. Rev. (2) 34, 198 [1929].

26 J. R. Platt and R. A. SAWYer, Physic. Rev. (2) 60, 866 [1941].

27 L. A. Sommer, Z. Physik. 45, 178 [1927]. 


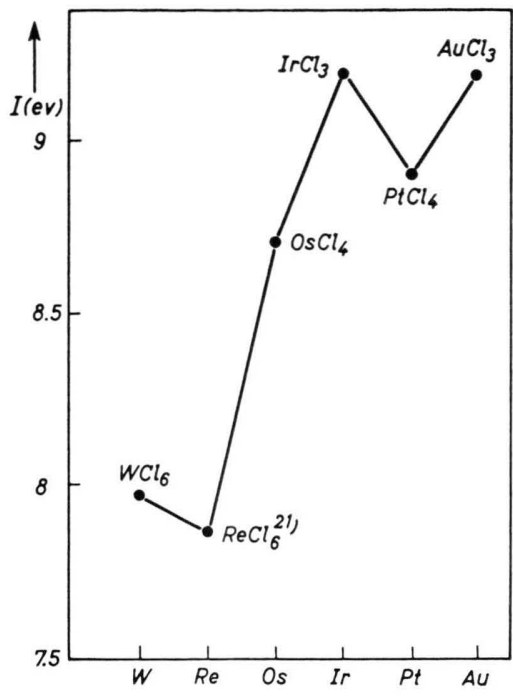

Fig. 2. Plot of the first ionization potential of third-row transition metals as a function of their highest valence-state chlorides as existing at $300^{\circ} \mathrm{K}$.

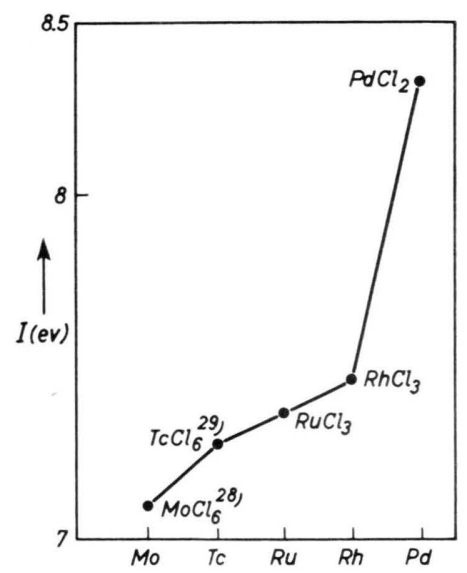

Fig. 3. Plot of the first ionization potential of second-row transition metals as a function of their highest valence-state chlorides as existing at $300^{\circ} \mathrm{K}$.

exist as chlorides at $300{ }^{\circ} \mathrm{K}$ in which the formal valence of the metal varies between +3 and +6 , with the first ionization potential of the metal, the plots have certainly an empirical value whatever their real significance may be. In the absence of any other information than the values of the first ionization potentials, it is impossible at the moment to be more precise. However, the good fit suggests that the variation of the first ionization potential in each row

28 M. Mercer, Chem. Commun. [London] 1967, 119.

29 R. Colton, Nature [London] 193, 872 [1962].

30 H. SCHÄFER, Chemische Transportreaktionen, page 13, Verlag Chemie, Weinheim 1962. parallels to a certain degree the variation of the higher ionization potentials, which themselves are not available. By this procedure the distribution of the hexachlorides among transition metals as presented in figs. 2 and 3 may be justified. Whether or not this same relationship holds for bromides and iodides of transition metals and also for actinide halides, can not be decided conclusively without more experimental data on these classes of compounds.

\section{Experimental section}

\section{a) General description of the preparative methods applied}

The black high-temperature form of $\mathrm{OsCl}_{4}$, usually synthesized from its elements ${ }^{7-9}$, is also obtained by reacting $\mathrm{OsO}_{4}$ with $\mathrm{CCl}_{4}$ at $743{ }^{\circ} \mathrm{K}$ in a sealed glass tube. $\mathrm{CCl}_{4}$, heated to $743{ }^{\circ} \mathrm{K}$, acts as a powerful chlorinating agent, and is aided in this respect by the high pressure generated. This reaction apparently in volves transport phenomena ${ }^{30}$ since the $\mathrm{OsCl}_{4}$ is entirely deposited at the colder end of the reaction vessel which is subjected to a small temperature gradient (the difference in temperature between the two ends in volved is approximately $70^{\circ}$ ). The reaction of $\mathrm{OsO}_{4}$ with $\mathrm{CCl}_{4}$ can be formulated as:

$$
\mathrm{OsO}_{4}+4 \mathrm{CCl}_{4} \stackrel{743 \stackrel{\circ}{\mathrm{K}}}{\rightarrow} \mathrm{OsCl}_{4}+4 \mathrm{COCl}_{2}+2 \mathrm{Cl}_{2} \text {. }
$$

As demonstrated by $x$-ray diffractometry and by magnetic measurements, a new, analytically well-defined dark brown crystal modification (low-temperature form) of $\mathrm{OsCl}_{4}$ is formed by heating, under reflux, a solution of $\mathrm{OsO}_{4}$ in $\mathrm{SOCl}_{2}$ :

$$
\mathrm{OsO}_{4}+4 \mathrm{SOCl}_{2} \stackrel{353^{\circ} \mathrm{K}}{\rightarrow} \mathrm{OsCl}_{4}+4 \mathrm{SO}_{2}+2 \mathrm{Cl}_{2} .
$$

Although the strong chlorinating properties ${ }^{31}$ of $\mathrm{SOCl}_{2}$ have been recognized, reaction (3), which leads to $\mathrm{OsCl}_{4}$, has never previously been exploited.

b) Preparation of the high-temperature form of $\mathrm{OsCl}_{4}$

$500 \mathrm{mg}$. of $\mathrm{OsO}_{4}$ was dissolved in $11 \mathrm{ml}$. of dry $\mathrm{CCl}_{4}$ which was saturated at $300{ }^{\circ} \mathrm{K}$ with dry, oxygen-free chlorine gas immediately before use. This solution. sealed in a thick-walled glass tube of $30 \mathrm{~cm}$. in length and $1 \mathrm{~cm}$. in diameter, was heated in a 1 meter furnace to $743{ }^{\circ} \mathrm{K}$ for 24 hours. The initial reaction temperature of $743{ }^{\circ} \mathrm{K}$ was then lowered to $653{ }^{\circ} \mathrm{K}$ and was maintained there for further 48 hours. At the end of this period heating was stopped and the furnace was al-

${ }^{31}$ H. Hecht, G. Jander, and H. Schlapmann, Z. anorg. allg. Chem. 254, 255 [1947]. 
lowed to cool down to $300{ }^{\circ} \mathrm{K}$. A black sublimate was deposited at the cooler end of the sealed glass tube. The tube was opened and the sublimate was heated in vacuo at $323{ }^{\circ} \mathrm{K}$ for three hours to remove excess of $\mathrm{CCl}_{4}$.

\section{c) Preparation of the low-temperature form of $\mathrm{OsCl}_{4}$}

$500 \mathrm{mg}$. of $\mathrm{OsO}_{4}$, dissolved in $75 \mathrm{ml}$. freshly distilled $\mathrm{SOCl}_{2}$, was heated under reflux for 12 hours at $353{ }^{\circ} \mathrm{K}$. Precautions were observed to prevent access of moist air, including the passage of dry nitrogen gas through the reaction vessel. Within 12 hours of reaction time under the experimental conditions specified, a dark brown precipitate was formed the purification of which was carried out in a glove box. Specifically, the excess of $\mathrm{SOCl}_{2}$ was decanted from the precipitate. The residue was then washed several times with petroleum ether to remove excess of $\mathrm{SOCl}_{2}$. This sample was finally heated at $373{ }^{\circ} \mathrm{K}$ in vacuo for three hours before being analysed.

COLTON and FARTHING ${ }^{\mathbf{1 4}}$ modified later this procedure ${ }^{1}$ by leaving a solution of $\mathrm{OsO}_{4}$ in $\mathrm{SOCl}_{2}$ for one week at $300{ }^{\circ} \mathrm{K}$.

\section{d) Elemental analysis}

In order to estimate both the osmium and the chlorine content of the reaction products isolated, the specimens were reduced to osmium metal in a current of dry hydrogen gas at $573{ }^{\circ} \mathrm{K}$ for 8 hours. The temperature was raised gradually from $300{ }^{\circ} \mathrm{K}$ to $573{ }^{\circ} \mathrm{K}$ in order to prevent loss of $\mathrm{OsCl}_{4}$ by sublimation. Finally the temperature was raised to $773{ }^{\circ} \mathrm{K}$ for 2 hours to complete the reaction. The amount of hydrogen chloride evolved as a result of the quantitative reduction of $\mathrm{OsCl}_{4}$ was absorbed in solutions of $\mathrm{NaOH}(2 \mathrm{~N})$. To displace all the hydrogen chloride released, the system was flushed with nitrogen gas at $300{ }^{\circ} \mathrm{K}$. The chlorine content was estimated gravimetrically by precipitation as $\mathrm{AgCl}$. The weight of the residue left over in the porcelain boat was used to estimate the content of osmium in $\mathrm{OsCl}_{4}$. The residue was identified by x-ray diffractometry to be pure osmium metal. An elemental analysis of the high-temperature form gave the following result:

$\begin{array}{lcl} & \% \mathrm{Os} & \% \mathrm{Cl} \\ \text { Experimental: } & 57.5 & 42.6 \\ \text { Theoretical: } & 57.27 & 42.73\end{array}$

An elemental analysis of the low-temperature form yielded:

$\begin{array}{rr}\% \mathrm{Os} & \% \mathrm{Cl} \\ 57.4 & 42.8\end{array}$

e) x-ray powder photographs

These were obtained at $300{ }^{\circ} \mathrm{K}$ using nickel-filtered $\mathrm{Cu}-\mathrm{K}_{a}$ radiation and two $\mathrm{D}$ e b y e $-\mathrm{S}$ c h e r r e r cameras of 5.73 and $11.48 \mathrm{~cm}$. diameters. The samples were contained in $0.5 \mathrm{~mm}$. Lindemann glass capillary tubes. The line intensities, I, were estimated visually on a 10 point scale.

\section{f) Magnetic measurements}

The magnetic susceptibilities were measured by the Gouy method with magnetic fields up to 10000 Oerstedts. The samples were finely powdered and carefully packed in one half of the tube. The tube was evacuated and appropriate corrections were made for its diamagnetism. None of the compounds had a field dependent susceptibility beyond experimental error. The complex $\mathrm{Hg}\left[\mathrm{Co}(\mathrm{SCN})_{4}\right]$ was used to calibrate ${ }^{32}$ the magnetic field.

The author thanks Professors K. Brodersen and F. FEHÉR for placing the basic materials at his disposal.

32 B. N. Figgis and R. S. Nyholm, J. chem. Soc. [London] 1958, 4190 . 